Check for updates

Cite this: RSC Adv., 2019, 9, 12718

Received 8th February 2019

Accepted 10th April 2019

DOI: $10.1039 / c 9 r a 01041 f$

rsc.li/rsc-advances

\section{Cholesterol-coated gold nanorods as an efficient nano-carrier for chemotherapeutic delivery and potential treatment of breast cancer: in vitro studies using the MCF-7 cell line}

\author{
Nouf N. Mahmoud, (D) *a Dima A. Sabbah, ${ }^{a}$ Rana Abu-Dahab, ${ }^{b}$ Duaa Abuarqoub, ${ }^{c}$ \\ Maha Abdallah, ${ }^{\mathrm{b}}$ Ameerah (Hasan Ibrahim) ${ }^{\mathrm{a}}$ and Enam A. Khalil ${ }^{\mathrm{b}}$
}

Gold nanorods (GNRs) have a recognized role in treatment of cancers as efficient nanocarriers for chemotherapeutic drug delivery. In this study, GNRs modified with cholesterol-PEG were employed as a nanocarrier for a hydrophobic compound having a promising phosphatidylinositol 3-kinase (PI3K $\alpha$ ) inhibitory activity. The acquired nanocomplex was characterized by optical and infra-red (IR) absorption spectroscopies, in addition to hydrodynamic size and zeta potential. Glide docking and superposing of docked poses of the hydrophobic ligand and cholesterol moiety demonstrated that hydrophobic interactions drive the conjugation and attachment of the ligand to the cholesterol moiety of the nanocarrier. In vitro release study under a cellular environment indicates that the presence of cells has enhanced the release and the cellular uptake of the conjugated ligand. Furthermore, the anti-proliferative assay of the nanocomplex revealed potent cytotoxicity over a low concentration range of the nanocomplex against MCF-7 breast cancer cells compared to the free compound or the nanocarrier alone. Analysis of cellular death modality by flow cytometry showed that the nanocomplex has a rapid effect on cell death, as cells went toward the late apoptotic/ necrotic stage rapidly and proportionally to the increase of the nanocomplex concentration. The overall results propose that cholesterol-decorated GNRs could be considered as a promising nanocarrier for hydrophobic drugs to achieve efficient delivery and potential therapy against breast cancer cells.

\section{Introduction}

Breast cancer is one of the major health burdens despite the rapid progress in cancer research and therapy. ${ }^{1}$ Classical chemotherapy is the first line of cancer treatment using cytotoxic chemotherapeutic agents that interfere with the process of cell division. However, the severe toxicity to normal tissues, such as hair loss, bone marrow toxicity, nausea and vomiting, in addition to poor bioavailability and targeting potentials, often limit the effectiveness of chemotherapy against cancers. ${ }^{2,3}$ Combined chemotherapy of two or more anticancer drugs has been extensively exploited to treat a variety of cancers. However, the toxicity of such combinations is still unreasonable.

Failure of numerous chemotherapeutic agents coupled with growing the understanding of cancer pathology urge the

${ }^{a}$ Faculty of Pharmacy, Al-Zaytoonah University of Jordan, Amman 11733, Jordan. E-mail: nouf.mahmoud@zuj.edu.jo

${ }^{b}$ School of Pharmacy, The University of Jordan, Amman 11942, Jordan ${ }^{c}$ Cell Therapy Center, The University of Jordan, Amman 11942, Jordan development of novel and targeted therapeutic platforms with minimal toxicity and resistance.

Nanoparticle-based approaches are distinctly attractive for breast cancer therapy, diagnosis and drug delivery owing to their tiny size, capability of surface modification using a variety of small ligands and biomacromolecules, and ability to accumulate into tumors owing to the enhanced permeability and retention effect. ${ }^{4,5}$

The employment of nanocarriers as drug delivery is a key strategy for treatment of cancers. Several types of nano-systems have been extensively investigated for chemotherapy delivery on a more effective and less toxic fashion, including polymers, liposomes, dendrimers, solid lipid and inorganic nanoparticles. ${ }^{6-11}$

Utilizing gold nanoparticles (GNPs) as delivery nano-systems is substantially examined in the literature due to ease of surface modifications and unique optical properties. ${ }^{12-14}$ GNPs of diverse sizes and surface chemistries were used for delivery of several drugs and biomacromolecules. ${ }^{15-17}$ For example, TAT peptide-functionalized GNPs were used to improve delivery and reduce toxicity of doxorubicin towards breast cancer metastasis 
to brain. ${ }^{18}$ Furthermore, conjugation of quercetin to GNPs has induced cell apoptosis in two cell lines of breast cancer. ${ }^{19}$

Although covalent conjugation of GNPs to thiolated ligands provides a considerable stability of the conjugates and produces a controlled release of the cargo, such a slow release may produce challenges for actual clinical applications. ${ }^{20}$ Accordingly, non-specific binding between nanocarriers and payloads is becoming a more efficacious approach for competent drug delivery and massive cellular uptake. ${ }^{20}$

In this work, a simple gold-based nano-platform was designed as a nanocarrier for a hydrophobic ligand into MCF-7 breast cancer cells. GNRs were synthesized using a low concentration of cetyl trimethylammonium bromide (CTAB) and their surfaces were modified and stabilized by a cholesterol moiety linked to a thiolated poly ethylene glycol (PEG) in order to enhance its colloidal stability and aqueous dispersibility. The modified GNRs (Chol-GNRs) were utilized to conjugate a small hydrophobic molecule, as a chemotherapeutic drug model, by non-covalent hydrophobic interactions with the hydrophobic pocket of the nanocarrier (the cholesterol moiety). Such noncovalent binding is supposed to enhance the delivery of the payload upon exposure to cells and ultimately will accelerate its cytotoxicity.

The hydrophobic compound used in this study is $\mathrm{N}$-(4hydroxyphenyl)4-hydroxy-2-quinolone-3-carboxamide

(Compound A), which is one of a new series of $\mathrm{N}$-substituted-4hydroxy-2-quinolone-3-carboxamides that were synthesized, characterized, and biologically evaluated previously in our lab, and they displayed a promising phosphatidylinositol 3-kinase (PI3K $\alpha$ ) inhibitory activity. ${ }^{21} \mathrm{PI} 3 \mathrm{~K} \alpha$ is responsible for synthesis of triphosphates that induce cell growth and division. ${ }^{22,23}$ In this study, Chol-GNRs were conjugated to Compound A and the obtained "nanocomplex" was characterized in terms of ultraviolet-visible (UV-vis) and infra-red (IR) absorption spectroscopies, hydrodynamic size, surface charge and in vitro release behavior. The cytotoxicity of the nanocomplex on MCF-7 breast cancer cell line and human dermal fibroblasts was investigated and the cellular death modality of the designed nanocomplex was assessed using flow cytometry assay.

\section{Experimental part}

\subsection{Chemical synthesis of GNRs solution}

GNRs solution was synthesized using a mixture of CTAB (SigmaAldrich Chemicals, USA) and sodium oleate (NaOL, SigmaAldrich Chemicals, USA) following a previous protocol with slight modifications. ${ }^{24}$ Briefly, seeds were prepared by adding sodium borohydride $\left(\mathrm{NaBH}_{4}, 99 \%\right)$, (Sigma-Aldrich Chemicals, USA) to a stirred solution of CTAB. A volume of $18.0 \mathrm{~mL}(4.0$ $\mathrm{mM})$ of silver nitrate $\left(\mathrm{AgNO}_{3}, 99 \%\right.$, Sigma-Aldrich Chemicals, USA) was transferred to a growth solution of CTAB and NaOL and kept under stirring for $15 \mathrm{~min}$. Chloroauric acid $(250 \mathrm{~mL}$, $1.0 \mathrm{mM})\left(\mathrm{HAuCl}_{4} \cdot 3 \mathrm{H}_{2} \mathrm{O}, 99.9 \%\right.$, Sigma-Aldrich Chemicals, USA) was transferred to the growth solution and the $\mathrm{pH}$ of the solution was adjusted by $\mathrm{HCl}$. Ascorbic acid (99\%, Sigma-Aldrich Chemicals, USA), and the seeds $(0.8 \mathrm{~mL})$ were added to the growth solution and the obtained mixture was kept undisturbed at $30{ }^{\circ} \mathrm{C}$ for $24 \mathrm{~h}$. GNRs solution was spun down twice by centrifugation (Centrifuge, Labofuge I, Heraeus Christ, Germany) for $10 \mathrm{~min}$ at $16580 \times g$, suspended in Milli-Q water and stored at $4{ }^{\circ} \mathrm{C}$.

\subsection{Surface modification of GNRs with cholesterol- polyethylene glycol-thiol (Chol-PEG-SH); Chol-GNRs}

A volume of $1.0 \mathrm{~mL}\left(25.0 \mathrm{mg} \mathrm{mL}^{-1}\right.$ ) of Chol-PEG-SH solution (MW $\sim 2000 \mathrm{~g} \mathrm{~mol}^{-1}$, Nanosoft Polymers, USA) was added to a solution of GNRs $(10.0 \mathrm{~mL})$ and kept under stirring overnight. The obtained modified GNRs solution was spun down by centrifugation twice for $10 \mathrm{~min}$ at $11510 \times g$ and were stored at $4{ }^{\circ} \mathrm{C}$.

\subsection{Surface modification of GNRs with methoxy- polyethylene glycol-thiol (m-PEG-SH); PEG-GNRs}

A volume of $1.0 \mathrm{~mL}$ of thiolated m-PEG solution $\left(10.0 \mathrm{mg} \mathrm{mL}^{-1}\right)$ (MW $2000 \mathrm{~g} \mathrm{~mol}^{-1}$, Sigma-Aldrich Chemicals, USA) was added to a solution of GNRs $(10.0 \mathrm{~mL})$ and kept under stirring overnight. The functionalized GNRs solution was spun down by centrifugation twice for $10 \mathrm{~min}$ at $11510 \times g$ and were stored at $4{ }^{\circ} \mathrm{C}$.

\subsection{Conjugation of Compound A into Chol-GNRs and PEG- GNRs to obtain Chol-A-GNRs and PEG-A-GNRs, respectively}

Compound A was synthesized in-house and fully characterized according to a previous published protocol. ${ }^{21}$ For conjugation of Compound A to the hydrophobic moiety of Chol-GNRs or PEGGNRs, $10 \mu \mathrm{L}$ of Compound A stock solution $\left(50 \mathrm{mg} \mathrm{mL}^{-1}\right.$ of dimethyl sulfoxide (DMSO)) was added to each $1.0 \mathrm{~mL}$ of CholGNRs or PEG-GNRs (2.0 nM), and the solution was kept under stirring for $4 \mathrm{~h}$ at room temperature. The nanocomplex solution was then spun down by centrifugation twice at $11510 \times g$ for $8 \mathrm{~min}$ to remove the unbound Compound A, and was suspended in phosphate buffer saline (PBS, pH 7.4).

\subsection{Characterization of GNRs, PEG-GNRs and cholesterol- coated GNRs; Chol-GNRs}

Chol-GNRs were characterized by optical absorption spectroscopy (UV-1800 spectrophotometer, Shimadzu, Japan), dynamic light scattering (DLS) and zeta potential (Nicomp Nano Z3000 zeta potential/particle size analyzer, CA, USA), in addition to transmission electron microscope (TEM) imaging (FEI Morgani 268 , operating voltage of $60 \mathrm{kV}$, Holland).

\subsection{Characterization of the nanocomplexes; Chol-A-GNRs and PEG-A-GNRs}

Chol-A-GNRs were characterized by optical absorption spectroscopy, DLS, effective surface charge and by Fourier-transform infrared (FTIR) spectroscopy (Shimadzu FTIR Affinity spectrophotometer, Japan). Potassium bromide (Acros, Belgium) was used to prepare the sample discs for FTIR spectroscopy. PEG-AGNRs were characterized by optical absorption spectroscopy, DLS and effective surface charge.

The amount of the conjugated Compound A $(\mu \mathrm{g})$ was estimated using a well validated UV-vis absorption spectroscopy method. A standard calibration curve of Compound A was 
obtained by measuring the UV-vis absorbance of known concentrations of Compound A in PBS (pH 7.4) at $297 \mathrm{~nm}$.

\subsection{Glide docking of Compound A and cholesterol moiety}

To explore the interaction of cholesterol moiety and Compound A, we performed Glide docking approach ${ }^{25-27}$ against homology modeled ${ }^{28}$ structure of phosphoinositide-3 kinase (PI3K $\alpha$ ) (PDB ID: $2 \mathrm{RD} 0) .{ }^{29}$ The structure was treated and energy minimized using the Protein Preparation and Macro Model wizards in Schrödinger ${ }^{27}$ software to maximize $\mathrm{H}$-bond interactions and reduce the steric clashes, respectively. Additionally, 3D models of cholesterol and Compound A were built using MAESTRO ${ }^{27}$ Build module and energetically minimized by the Macro Model panel recruiting the OPLS2005 force field.

\subsection{In vitro release study of Compound $A$ from the nanocomplex (Chol-A-GNRs) in PBS or tissue culture medium}

A volume of $1.0 \mathrm{~mL}$ of the nanocomplex ( $80 \mu \mathrm{g} \mathrm{mL} \mathrm{m}^{-1}$ of gold) were transferred into a dialysis bag (MWCO 12-14 kD, Spectrum Lab, USA) which was placed in a glass vial containing $50.0 \mathrm{~mL}$ of PBS (pH 7.4) or tissue culture medium; Roswell Park Memorial Institute medium (RPMI) 1640 medium (Euroclone, Europe) in 0.1\% Tween 80 to facilitate the solubility of the compound. Then, the vials were placed into a shaking water bath $\left(37^{\circ} \mathrm{C}, 120 \mathrm{rpm}\right)(\mathrm{GFL}$ 1083, Burgwedel, Germany). The same experiment was conducted for the nanocarrier alone (Chol-GNRs) to exclude any interference.

A volume of $0.5 \mathrm{~mL}$ of the release media was removed at specific time intervals $(0.5,1,2,3,4,5,6,24,48$ and $72 \mathrm{~h})$ and replaced with a fresh $\mathrm{PBS}(\mathrm{pH} 7.4)$ or tissue culture medium to keep the sink condition. The concentration $\left(\mu \mathrm{g} \mathrm{mL}{ }^{-1}\right)$ and subsequently the amount $(\mu \mathrm{g})$ of Compound $\mathrm{A}$ in the removed media was estimated by measuring the optical absorbance at each time point at $297 \mathrm{~nm}$ against a standard calibration curve of Compound A in PBS ( $\mathrm{pH} 7.4$ ) or tissue culture medium containing Tween $80(0.1 \%)$. The release profile of Compound A was presented as percentage of released cumulative amount $v s$. time. The results represent the average of four independent experiments.

\subsection{In vitro release study of Compound A from the nanocomplex (Chol-A-GNRs) under cellular environment}

In order to predict the effect of cells on the release pattern of Compound A from the nanocomplex, the release study was performed under cellular environment. A density of $2 \times 10^{5}$ of MCF-7 cells were seeded into 6-well plates in $3.0 \mathrm{~mL}$ of tissue culture medium (RPMI) for each well and kept attaching for $48 \mathrm{~h}$ (in three replicates). Then, the freshly prepared dilution of Chol-A-GNRs in the cell culture medium without FBS to appropriate concentrations of the nanocomplex $\left(20.0 \mu \mathrm{g} \mathrm{mL}^{-1}\right.$ of gold) was immediately added to the cells. Untreated cells were considered as control in each experiment.

The concentration of Compound A $\left(\mu \mathrm{g} \mathrm{mL}^{-1}\right)$ in the supernatant of each treatment $v s$. control (untreated cells) at different time intervals $(60,120$ and $240 \mathrm{~min})$ was estimated by measuring the optical absorbance of the supernatants at $297 \mathrm{~nm}$ after centrifuging the media for $8 \mathrm{~min}$ at $11510 \times \mathrm{g}$. The amount of Compound A released into the tissue culture medium under cellular environment was estimated against a standard calibration curve of the compound.

\subsection{Anti-proliferative activity against MCF-7 and human dermal fibroblasts cell lines}

2.10.1 Cell culture. MCF-7 breast cancer cells and human dermal fibroblasts (American Type Culture Collection (ATCC), USA) were maintained in RPMI 1640 medium and Iscove's Modified Dulbecco's Medium (IMDM, Eurobio, France), respectively and supplemented with $10 \%$ (v/v) FBS, $1 \%$ of $2.0 \mathrm{mM} \mathrm{L}$-glutamine, $1.0 \%(\mathrm{v} / \mathrm{v})$ of penicillin $\left(100 \mathrm{U} \mathrm{mL}^{-1}\right) /$ streptomycin $\left(100 \mu \mathrm{g} \mathrm{mL}{ }^{-1}\right)$ and $1.0 \mathrm{~mL}$ of Gentamycin (Euroclone, Europe) under $5 \% \mathrm{CO}_{2}$ and $99 \%$ relative humidity at $37{ }^{\circ} \mathrm{C}$. After the cells became confluent, they were trypsinised (trypsin, Euroclone, Europe), stained with trypan blue (0.04\%) (Gibco, USA) and counted by a hemocytometer.

2.10.2 Determination of half maximal inhibitory concentration $\left(\mathrm{IC}_{50}\right)$ of Compound A against MCF-7 breast cancer cell line. Compound A was dissolved in DMSO, a biocompatible solvent commonly used for cytotoxicity assay of poorly soluble compounds, and then diluted in tissue culture medium to obtain the following concentrations: 7.8, 15.62, 31.25, 62.5, 125, $250,500 \mu \mathrm{g} \mathrm{mL}{ }^{-1}$. The concentration of DMSO in all treatment groups was not exceeded $1.5 \%$. The experiment was done in triplicate and the $\mathrm{IC}_{50}$ was estimated for Compound A using GraphPad Prism, version 7.0.

2.10.3 Anti-proliferative activity of Chol-A-GNRs, free Compound $A$ and Chol-GNRs against MCF-7 breast cancer cells and human dermal fibroblasts. Volumes of $100 \mu \mathrm{L}$ of cell suspension of $5 \times 10^{3}$ and $10 \times 10^{3}$ cell per well for breast cancer cells (MCF-7) and human dermal fibroblasts, respectively were seeded in 96-well plates and were incubated for $24 \mathrm{~h}$. After that, $100 \mu \mathrm{L}$ per well of Chol-A-GNRs $(0.156 / 0.2,0.625 / 0.75$, 2.5/3.125, 10.0/12.5, and 40.0/50.0 $\mu \mathrm{g} \mathrm{mL} \mathrm{m}^{-1}$ of Chol-GNRs/ Compound A), Chol-GNRs (0.156, 0.625, 2.5 and $10.0 \mu \mathrm{g}$ $\left.\mathrm{mL}^{-1}\right)$ and the corresponding concentrations of Compound $\mathrm{A}$ $\left(0.2,0.75,3.125,12.5 \mu \mathrm{g} \mathrm{mL}^{-1}\right)$ were added to the plates in three replicates. FBS was not added to the tissue culture media to prevent aggregation of GNRs upon mixing with the media. The plates were incubated for $72 \mathrm{~h}$ and the cellular cytotoxicity was analyzed using the Sulforhodamine B (SRB) assay (SigmaAldrich Chemicals, USA). Ice-cold $40 \%$ trichloroacetic acid was used to fix the cells and they were incubated at $4{ }^{\circ} \mathrm{C}$ for $1 \mathrm{~h}$. Then, the plates were washed with cold water five times and left at room temperature. SRB stain was added to the wells for $30 \mathrm{~min}$, and then were washed with $1.0 \%$ acetic acid. After drying at room temperature, Tris base $(100 \mu \mathrm{L}, 10.0 \mathrm{mM}, \mathrm{pH}$ 10.5) was added to each well and the plates were shaken for 15 min using a plate shaker, then the absorbance of each well was recorded by ELISA plate reader at $570 \mathrm{~nm}$. Cell viability was calculated relative to the absorbance of the negative control, which presented $100 \%$ cell viability. The experiment was done in triplicate. 
2.11 Quantification of the cellular uptake of Chol-GNRs and PEG-GNRs into MCF-7 breast cancer cell line and human dermal fibroblasts by ICP-OES

A density of $2 \times 10^{6}$ cells of MCF-7 were seeded into $25 \mathrm{~cm}^{2}$ flasks in $12.0 \mathrm{~mL}$ tissue culture media and kept attaching for 48 hours. Then, the freshly prepared dilutions of PEG-GNRs or Chol-GNRs in tissue culture medium $\left(20.0 \mu \mathrm{g} \mathrm{mL}{ }^{-1}\right.$ of gold) without FBS were added to the cells and incubated for $3 \mathrm{~h}$. After two washing steps with PBS, the cells were trypsinized and collected after centrifugation for $30 \mathrm{~min}$ at $4{ }^{\circ} \mathrm{C}$. The collected pellets were digested with fresh aqua regia $\left(\mathrm{HNO}_{3}\right.$ and $\mathrm{HCl}$; $1: 3)$ and kept in a water bath $\left(60-70{ }^{\circ} \mathrm{C}\right)$ for $3 \mathrm{~h}$, then, diluted with Milli-Q water up to $4.0 \mathrm{~mL}$, filtered by Teflon syringe filter $(0.22 \mu \mathrm{m})$ and analyzed by ICP-OES (Optima 2000 DV, ICP-OES, PerkinElmer, USA). Untreated cell were presented as control in each experiment. The same previous cellular uptake experiment of Chol-GNRs and PEG-GNRs was performed using human dermal fibroblasts. The experiments were done in triplicate.

Gold was quantified at $242.795 \mathrm{~nm}$ and the concentration of gold was estimated against a standard calibration curve of gold standard for ICP (1000 ppm, Sigma-Aldrich Chemicals, USA) (0.1-10.0 ppm). The measurements were performed in triplicate.

\subsection{Cell death analysis by flow cytometry}

2.12.1 Apoptosis analysis. To explore the effect of Chol-AGNRs on the growth inhibition of MCF-7 cell line; cell death was investigated by flow cytometry using annexin V/PI apoptosis kit (Molecular Probes, USA).

MCF-7 cells $\left(4 \times 10^{5}\right.$ cells $)$ were seeded into 6-well plates, then they were treated with Chol-A-GNRs $\left(4.0\right.$ and $8.0 \mu \mathrm{g} \mathrm{mL}^{-1}$ of gold). After $24 \mathrm{~h}$, the cells were collected by trypsin EDTA $0.25 \%$, washed with PBS, and the obtained pellets were stained with annexin V/PI dye according to the manufacturer's instructions. Doxorubicin $(1.0 \mu \mathrm{M}$, Doxil) was used as a positive control. Cell death modality, either apoptosis or necrosis, was analyzed by fluorescein activated sorter FACS Canto II, Becton Dickinson (BD) Biosciences, USA.

2.12.2 Cell cycle analysis. The nuclear DNA contents of MCF-7 cells pre-treated with Chol-A-GNRs $\left(8.0 \mu \mathrm{g} \mathrm{mL}{ }^{-1}\right.$ of gold $)$ were analyzed by flow cytometry after $24 \mathrm{~h}$ of treatment. Around $0.5 \times 10^{6}$ of treated MCF-7 cells were stained with propidium iodide (PI) (Thermo Fisher Scientific, USA) according to the manufacturer's protocol. Cells were analyzed immediately using fluorescein activated sorter FACS Canto II, Becton Dickinson (BD) Biosciences, USA. To determine cell cycle phases; samples were analyzed by FCX express software.

\subsection{Statistical analysis}

Statistical analysis was conducted by unpaired $t$-test by GraphPad Prism version 7.0. Results are considered significant when $p$ $<0.05$.

\section{Results and discussion}

\subsection{Chemical synthesis and characterization of GNRs and Chol-GNRs}

In this study, GNRs were synthesized, characterized and modified with a cholesterol moiety linked to a thiolated-PEG moiety (Fig. 1A and C). Such gold-based nanocarrier was employed as a template to conjugate a hydrophobic chemical molecule, as a hydrophobic chemotherapeutic drug model (Compound A) (Fig. 1B) into the hydrophobic pocket of cholesterol-decorated gold nanocarrier.

The method used in this study to prepare GNRs was based on utilizing a mixture of CTAB and oleic acid instead of CTAB alone

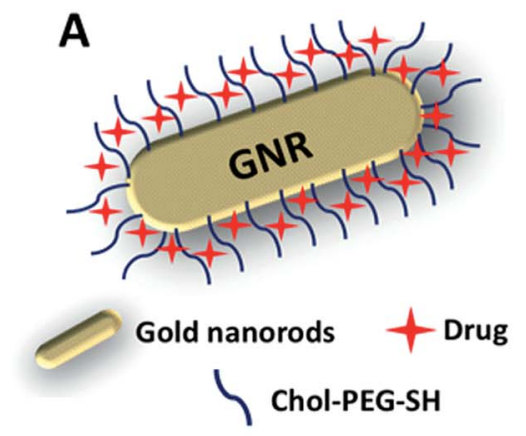<smiles>O=C(Nc1ccc(O)cc1)c1c(O)c2ccccc2[nH]c1=O</smiles>

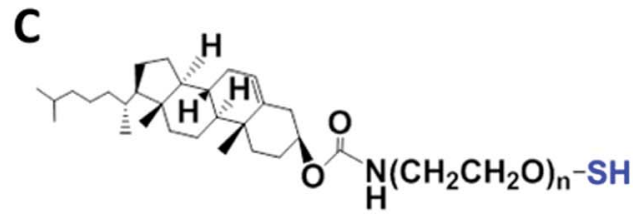

Fig. 1 Illustration demonstrates the nanocomplex (A) of Chol-GNRs conjugated with Compound A (B) by non-covalent hydrophobic interactions Compound $\mathrm{A}$ and the cholesterol moiety that linked to a thiolated PEG (C). 
to acquire GNRs with an aspect ratio (AR) of $\sim 4$. The prepared GNRs has a low concentration of CTAB which has a welldocumented cytotoxicity. ${ }^{30,31}$ The concentration of CTAB that bound to the surface of GNRs was further reduced by effective surface modification with a cholesterol moiety that was linked to a thiolated PEG. PEG has a pivotal role in enhancing the colloidal stability of the nanoparticles upon cellular exposure since it retards the non-specific adsorption of biomacromolecules by steric repulsion in addition to enhancing the aqueous dispersibility of Chol-PEG-SH in water. ${ }^{32}$ Besides, the PEG moiety extends blood circulation time, and ultimately increases specific tumor accumulation via the EPR effect. ${ }^{33}$ On the other hand, the presence of thiol in the molecule facilitated the effective displacement of the surface bound CTAB by cholesterol moiety via a strong covalent bond between thiol and gold (S-Au). ${ }^{34}$

The synthesized GNRs using a mixture of CTAB and oleic acid displayed a typical optical absorption profile with a small transverse peak and an intense longitudinal peak at $\sim 530 \mathrm{~nm}$ and $\sim 850 \mathrm{~nm}$, respectively (Fig. 2A). After surface modification of GNRs with PEG-SH or Chol-PEG-SH moiety, a small shift of the longitudinal peak was observed, however, no significant tailing or broadening of the plasmon peaks was reported, indicating a good colloidal stability of the cholesterol-modified GNRs (Fig. 2A). Furthermore, an extra optical absorption peak was observed for GNRs functionalized with cholesterol moiety at $\sim 250 \mathrm{~nm}$, that is corresponding to the optical absorption peak of Chol-PEG-SH dispersed in water (Fig. 2A). Moreover, the hydrodynamic size of GNRs upon surface modification with Chol-PEG-SH was increased to $\sim 64 \mathrm{~nm}$ and the effective surface charge was reduced to an almost neutral for both PEGylated and cholesterol-modified GNRs which confirm the successful replacement of the surface-bound CTAB with PEG or cholesterol-PEG-SH moieties (Fig. 2C). The shape and size of the synthesized GNRs and Chol-GNRs were further verified by TEM imaging; Fig. 2D shows a representative TEM image of GNRs having a rod-like shape nanoparticles of average length and width of $\sim 52.1$ and $\sim 12.5 \mathrm{~nm}$, respectively and an average corresponding aspect ratio (AR) of $\sim 4$. The shape and size of GNRs upon conjugation with Chol-PEG-SH were verified by TEM imaging which revealed a rod-like shape nanoparticles having average length and width of $\sim 54.1 \mathrm{~nm}$ and $\sim 12.4 \mathrm{~nm}$, respectively, and an average corresponding aspect ratio (AR) of $\sim 4$ (Fig. 2E).

\subsection{Conjugation of Compound A to the surface of Chol- GNRs or PEG-GNRs and characterization of the "nanocomplexes"; Chol-A-GNRs and PEG-A-GNRs}

Hydrophobic drugs are the most commercially available drugs. However, loading hydrophobic drugs to aqueous nano-systems is considered as a real challenge. Conjugation of a hydrophobic
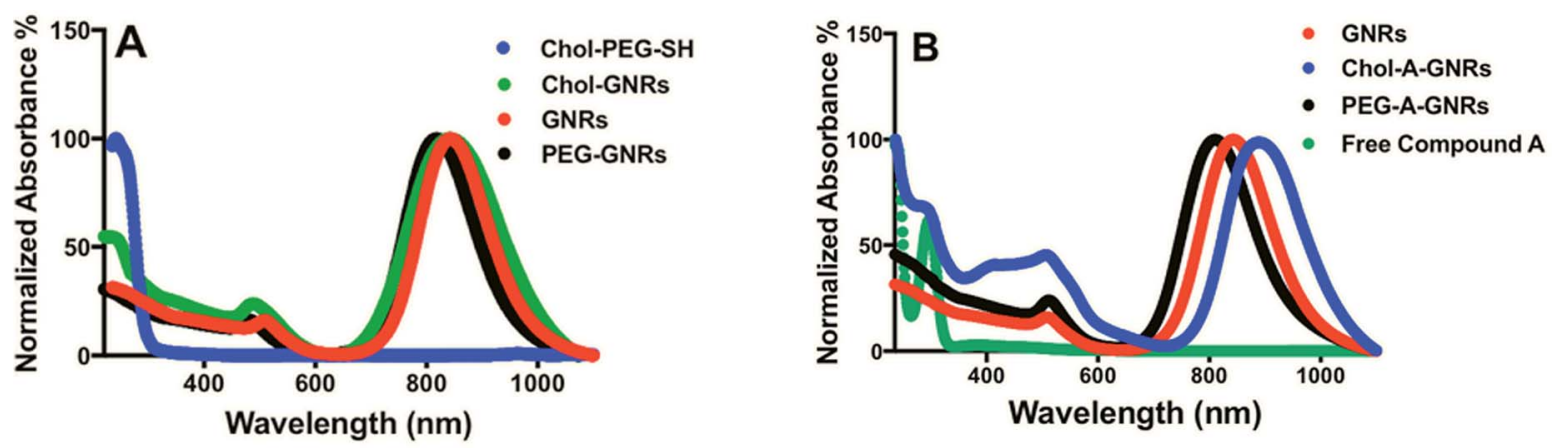

\begin{tabular}{ccc}
\hline $\mathrm{C}$ & $\begin{array}{c}\text { Hydrodynamic } \\
\text { Size }(\mathrm{nm})\end{array}$ & $\begin{array}{c}\text { Surface } \\
\text { Charge }(\mathrm{mV})\end{array}$ \\
\hline GNRs & $57.6 \pm 3.2$ & $+26.0 \pm 0.3$ \\
\hline Chol-GNRs & $64.3 \pm 2.9$ & $-3.0 \pm 0.8$ \\
\hline Chol-A-GNRs & $66.9 \pm 2.6$ & $+5.5 \pm 1.9$ \\
\hline PEG-GNRs & $61.9 \pm 0.9$ & $+2.5 \pm 2.1$ \\
\hline PEG-A-GNRs & $59.9 \pm 1.8$ & $+3.9 \pm 1.7$ \\
\hline
\end{tabular}
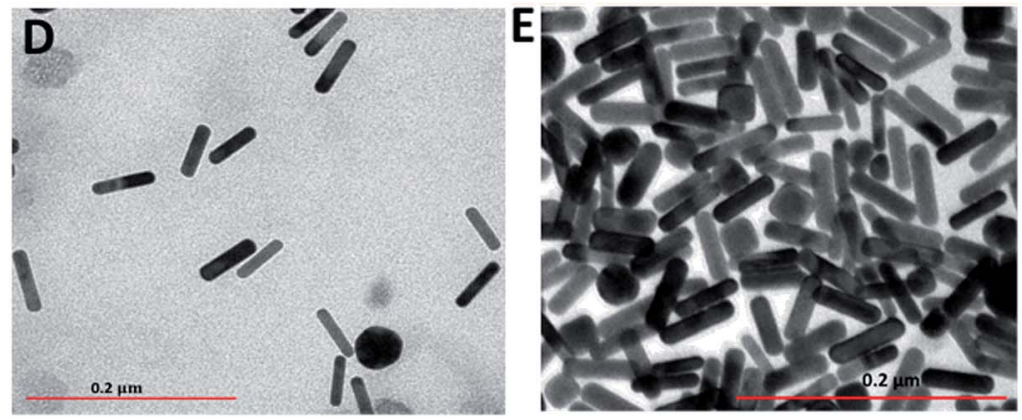

Fig. 2 Characterization of GNRs, Chol-GNRs, PEG-GNRs, Chol-A-GNRs and PEG-A-GNRs. (A) Optical absorption spectra of GNRs, Chol-GNRs, PEG-GNRs and Chol-PEG-SH dispersed in water. An extra peak was observed in the optical spectrum of Chol-GNRs at $\sim 250 \mathrm{~nm}$ which confirms the successful surface modification. (B) Optical absorption spectra of GNRs, Compound A in PBS, Chol-A-GNRs and PEG-A-GNRs. An extra absorption peak was observed at $\sim 297$ for Chol-A-GNRs which confirms the successful conjugation of Compound A to Chol-GNRs. (C) Hydrodynamic sizes and effective surface charges of GNRs, Chol-GNRs, Chol-A-GNRs, PEG-GNRs and PEG-A-GNRs. The size of Chol-GNRs was increased due to functionalization with Chol-PEG-SH, however, no significant change in the size and charge of Chol-A-GNRs upon conjugation with Compound A. (D) TEM image of GNRs that confirms a rod-shape of the nanoparticles having average length and width of $\sim 52.1 \mathrm{~nm}$ and $\sim 12.5 \mathrm{~nm}$, respectively, and an AR of $\sim 4$. (E) TEM image of Chol-GNRs that confirms the rod-shape of the nanoparticles having average length and width of $\sim 54 \mathrm{~nm}$ and $\sim 12.5 \mathrm{~nm}$, respectively, and an AR of $\sim 4$. 
molecule into the hydrophobic pocket of nano-system mediates the proper release of the loaded compound through hydrophobic interactions of the compound with the hydrophobic sites of the cellular membrane. ${ }^{20}$

In the current study, the synthesized Chol-GNRs were used as a nanocarrier of a small hydrophobic molecule; Compound A, that was synthesized previously by our research group by the structure-based drug design as a targeted agent for treatment of cancers such as colon and breast cancers by inhibiting PI3K $\alpha$. This study presents a facile and simple method for efficient conjugation of Compound A into the hydrophobic pocket of cholesterol-modified GNRs. Compound A has an intense optical absorption peak at $297 \mathrm{~nm}$ (Fig. 2B). Chol-GNRs conjugated to Compound A demonstrated typical transverse and longitudinal optical absorption peaks without significant broadening or tailing of the peaks, in addition to another peak at $\sim 297 \mathrm{~nm}$ that is corresponding to the conjugated compound (Fig. 2B).

PEG-A-GNRs showed no characteristic optical absorption peak at $\sim 297 \mathrm{~nm}$, suggesting its poor ability to conjugate the hydrophobic drug (Fig. 2B).

The obtained nanocomplex (Chol-A-GNRs) was characterized by their hydrodynamic size and effective surface charge. Conjugation of Compound A to Chol-GNRs was resulted in slight change in hydrodynamic size and similar surface charge compared to that of Chol-GNRs (Fig. 2C). However, PEG-A-GNRs demonstrated no significant change in the hydrodynamic diameter upon conjugation with Compound A (Fig. 2C).

The amount of Compound A conjugated to Chol-GNRs was estimated using a validated optical absorption spectroscopy method against a standard calibration curve of known concentrations of Compound A in PBS. We found that for each $1.0 \mathrm{~mL}$ of Chol-GNRs $(2.0 \mathrm{nM}), \sim 202 \mu \mathrm{g} \pm 4.2 \mu \mathrm{g}$ of Compound A was conjugated to the hydrophobic region of Chol-GNRs and the drug loading percentage on Chol-GNRs was around $41 \%$ relative to the initial amount of the drug.

On the other hand, $\sim 60 \mu \mathrm{g} \pm 9.2 \mu \mathrm{g}$ of Compound A were conjugated into PEG-GNRs, and the drug loading percentage was around $12 \%$ relative to the initial amount of drug. These results indicate the crucial role of cholesterol moiety in conjugating the hydrophobic drug into GNRs by hydrophobic interactions between their similar hydrophobic core structures.

Furthermore, the successful surface modification of GNRs with cholesterol moiety and Compound A was evaluated by comparing the FTIR spectra of the free Compound A and CholGNRs to that of the nanocomplex (Chol-A-GNRs). The detailed description of FTIR spectrum of the Compound A was described previously. ${ }^{21}$ Briefly, FTIR spectrum of Compound A showed the following characteristic bands: 3340 (-OH stretching), $3078 \mathrm{~cm}^{-1}$ (-CH stretching), 2870-2816 $\mathrm{cm}^{-1}$ (-NH stretching), $1913 \mathrm{~cm}^{-1}$ ( $\mathrm{C}=\mathrm{C}$ stretching), $1658 \mathrm{~cm}^{-1}(-\mathrm{C}=\mathrm{O}$ amide in ring stretching), $1612 \mathrm{~cm}^{-1}(-\mathrm{C}=\mathrm{O}$ external amide stretching), $1404 \mathrm{~cm}^{-1}$ (-C-O stretching), $1234 \mathrm{~cm}^{-1}$ (-C-C stretching) (Fig. 3). The nanocarrier alone (Chol-GNRs) demonstrated the following characteristic bands: $3325 \mathrm{~cm}^{-1}$ (-CH stretching), $2870 \mathrm{~cm}^{-1}$ (-NH stretching), $1714 \mathrm{~cm}^{-1}$ ( $-\mathrm{C}=\mathrm{O}$ ester stretching), $1110 \mathrm{~cm}^{-1}$ (-C-O stretching) (Fig. 3). On the other hand, the following characteristic bands of the nanocomplex (Chol-A-
GNRs) clearly confirm the successful decoration of GNRs with both cholesterol moiety and Compound A: $3336 \mathrm{~cm}^{-1}(-\mathrm{OH}$ stretching), 2860-2920 $\mathrm{cm}^{-1}$ (-NH stretching), $1690 \mathrm{~cm}^{-1}(-\mathrm{C}=$ $\mathrm{O}$ ester stretching), $1650 \mathrm{~cm}^{-1}(-\mathrm{C}=\mathrm{O}$ amide in ring stretching), $1608 \mathrm{~cm}^{-1}(-\mathrm{C}=\mathrm{O}$ external amide stretching $)$ and $1221 \mathrm{~cm}^{-1}$ (-C-O stretching) (Fig. 3). FTIR spectra of Compound A, CholGNRs and Chol-A-GNRs revealed similarities in the absorption peaks with slight shifts suggesting successful conjugation of Compound A to the cholesterol moiety of GNRs by hydrophobic interactions occurred between their structural backbones (Fig. 3).

\subsection{Glide docking and superposing of docked poses of Compound A and cholesterol moiety}

In order to understand the prospective interaction between Compound A and the cholesterol moiety, we carried out a Glide docking approach ${ }^{25-27}$ against the active domain of phosphoinositide-3-kinase $\alpha$ (PI3K $\alpha$ ) (PDB ID: 2RD0) (Fig. 4A and $\mathrm{B}$ ) and superposed the docked poses of cholesterol and Compound A (Fig. 5A-C). The superposing tactic illustrates that hydrophobic interaction drives the attachment of Compound $\mathrm{A}$ to cholesterol. Fig. 5A-C show overlapping of hydrophobic motifs of both compounds in different positions. The values of root mean square distance of superposed atoms in both compounds range from $2.803-2.820 \AA$; these values infer that overlaying of similar core structures might presides hydrophobic interaction, and the hydrophobic backbones of both cholesterol and Compound A enhance their binding interaction.

\subsection{In vitro release of Compound A from the nanocomplex; Chol-A-GNRs in PBS, tissue culture medium and under cellular environment}

The release pattern of Compound A that was conjugated to Chol-GNRs nano-system was studied in both PBS (pH 4.7) and the tissue culture medium (RPMI 1640). As shown in Fig. 6A, no burst release of the drug was observed and less than $45 \%$ of the drug was released over the first $6 \mathrm{~h}$. However, the release was much slow afterward and reached an almost complete release after $72 \mathrm{~h}$ (Fig. 6A). On other hand, the release pattern of Compound A in the tissue culture medium was similar to that in PBS, however, it was slightly faster and reached $\sim 100 \%$ after $48 \mathrm{~h}$ (Fig. 6A). The release behavior of the drug in both PBS and the tissue culture medium reflects the strength of the hydrophobic interaction between Compound A and the Chol-GNRs carrier.

Since the release of the compound in PBS or the medium does not exactly resemble the real situation, the release of Compound A was examined upon exposure to cells under cellular environment. Generally, hydrophobic drugs are preferentially up-taken into lipids and hydrophobic sites such as cellular lipid membrane which maximize their cellular uptake. ${ }^{20}$

Thus, we further examined the compound release profile when the nanocomplex was exposed to cancer cells under cellular environment. The MCF-7 cells were incubated with Chol-A-GNRs, and at predetermined time intervals from $30 \mathrm{~min}$ 


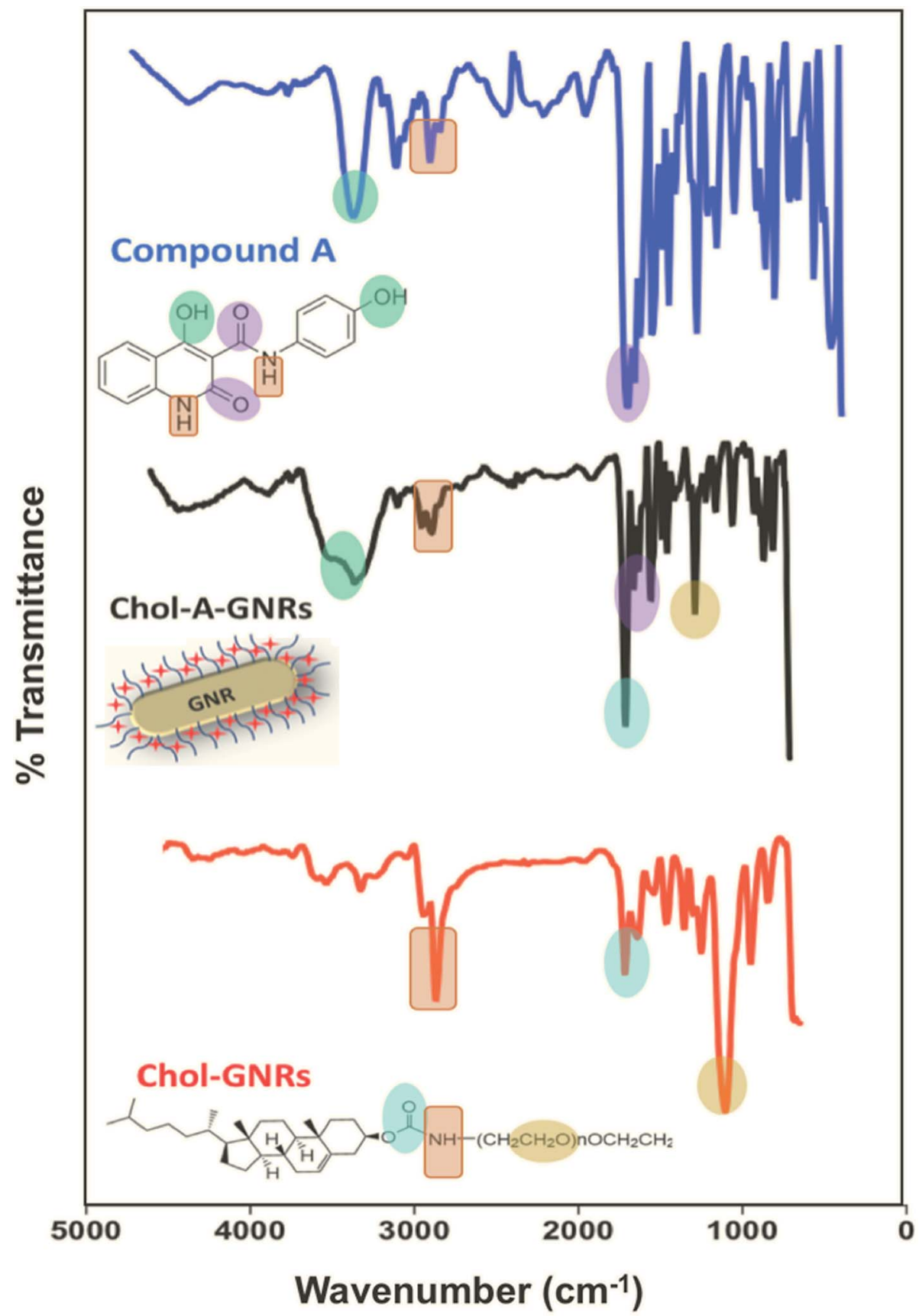

Fig. 3 Infra-red spectra of Compound A, Chol-GNRs and Chol-A-GNRs revealed similarities in the core structures' peaks with slight shifts suggesting successful conjugation of Compound A to the cholesterol moiety of GNRs by hydrophobic interactions occurred between their structural backbones.

to $240 \mathrm{~min}$, the amount of the released Compound A was recorded by measuring the optical absorbance at $297 \mathrm{~nm}$ of the supernatant after centrifuging the medium. The release of the compound was $\sim 43 \%$ after $1 \mathrm{~h}$ of incubation and it was reduced over time and reached $\sim 20 \%$ after 4 h of incubation under cellular environment (Fig. 6B). Clearly, the presence of cells enhanced the compound release from the nanocomplex and might accelerate the cellular uptake of the compound, which may be due to the lipophilicity of the cell membrane. ${ }^{20}$ Similarly, Ren et al. have found that the release of paclitaxel from GNRs stabilized with PEG linked to 11-mercaptoundecanoic acid was accelerated in the presence of cancer cells compared to drug release in PBS or serum due to the lipophilicity of the cell membrane which enhances the uptake of hydrophobic drugs. ${ }^{35}$

Obviously, the release of Compound A from the nanocomplex was slightly fast in tissue culture medium compared to PBS, and the release was accelerated in the presence of cells compared to PBS or tissue culture medium. 

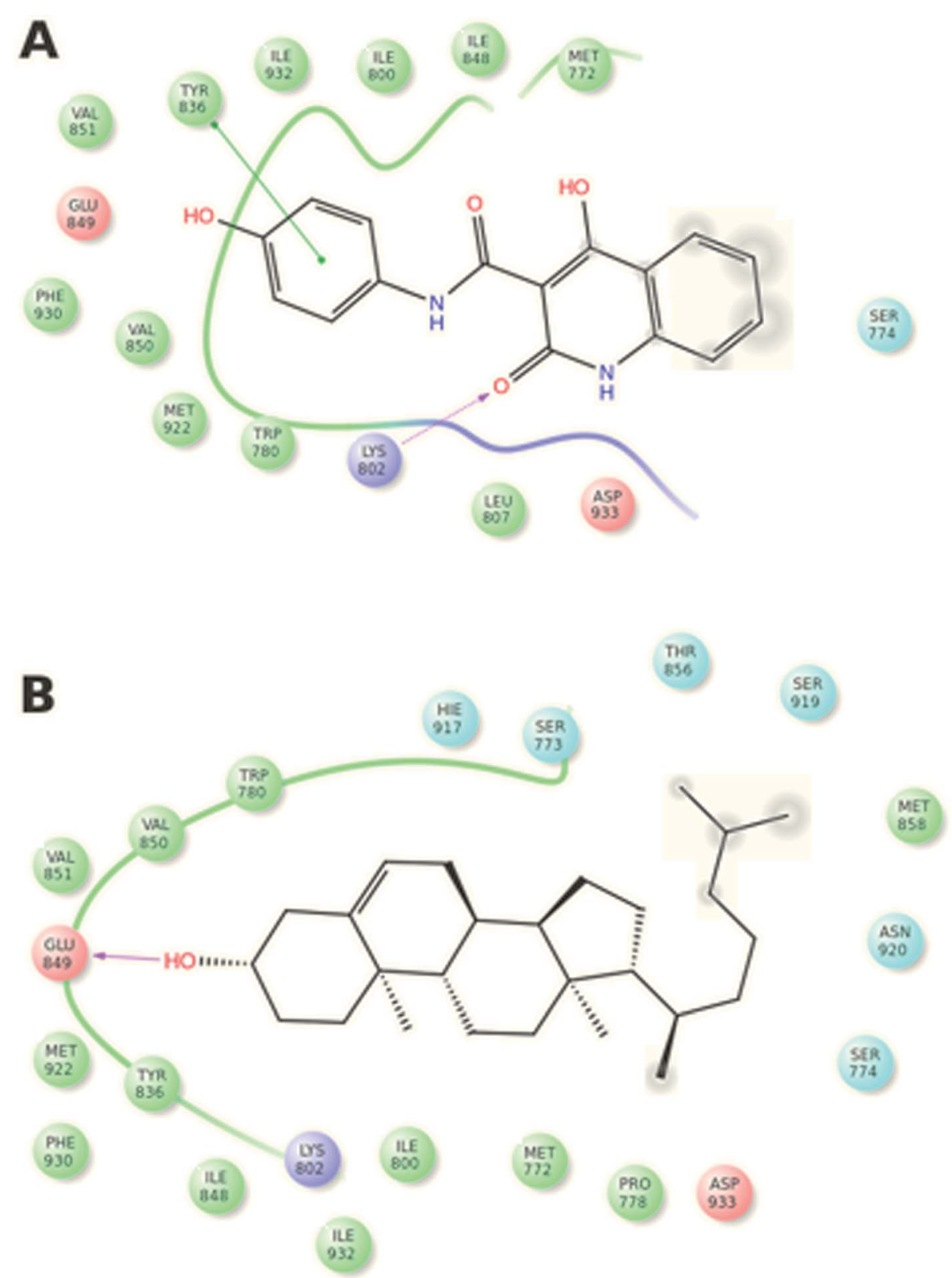

Fig. 4 Glide docking and complex formation of Compound A/PI3K $\alpha(A)$ and cholesterol/PI3K $\alpha$ (B).

\subsection{Cellular uptake of Chol-GNRs and PEG-GNRs into MCF-7 breast cancer cells and human dermal fibroblasts}

The cellular uptake of gold into the breast cancer cells was quantified using a well validated ICP-OES method. Fig. 6C shows an average of $\sim 15 \%$ of the applied dose of GNRs were penetrated into the cells compared to PEGylated nanorods which demonstrated an average penetration of $5 \%$ after $3 \mathrm{~h}$ of incubation with the cells. Besides the principal role of Chol-AGNRs in the effective delivery of the hydrophobic ligand into cancer cells, the detected cellular uptake of GNRs may be responsible for the possible synergistic cytotoxicity for the Compound A and the nanocarrier (Chol-GNRs). Kim et al. have designed gold-based nanoparticles having a hydrophobic pocket and a hydrophilic shell containing a zwitterionic head group for delivery of three different hydrophobic ligands into MCF-7 cells. They have reported that such a nano-system has demonstrated an efficient cellular uptake of the drug into the cells with a little uptake into the cancer cells. ${ }^{20}$

On the other hand, the cellular uptake of Chol-GNRs or PEGGNRs into the human dermal fibroblasts was less than $7 \%$ compared to the uptake of Chol-GNRs into the breast cancer cells $(\sim 15 \%)$.

\subsection{Anti-proliferative activity of Compound A, Chol-GNRs} and nanocomplex (Chol-A-GNRs) against MCF-7 breast cancer cell line and human dermal fibroblasts

The cytotoxicity of Compound A as free drug was investigated against MCF-7 breast cancer cells and human dermal 


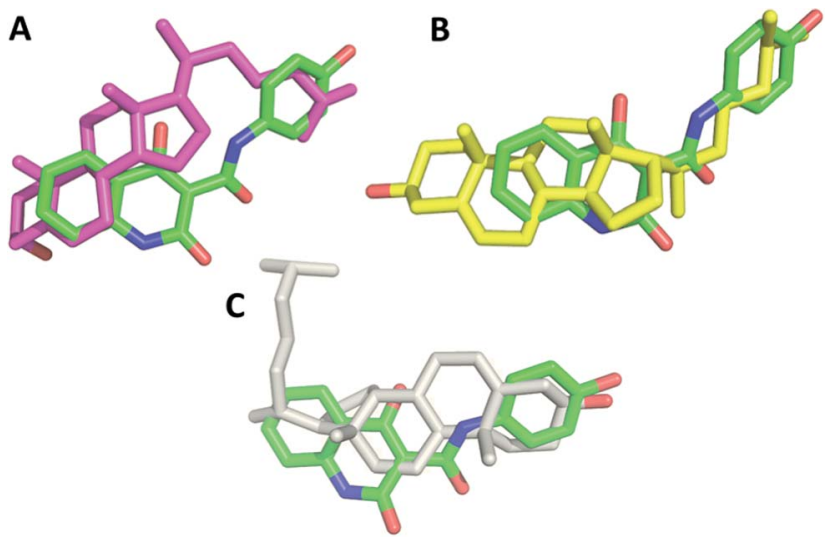

Fig. 5 Superposing of docked poses of cholesterol and Compound A in 3D models. The best docked poses of Compound A and cholesterol are extracted and overlaid to each other. The hydrophobic interaction drives the attachment of Compound A to cholesterol moiety where hydrophobic carbon backbone motifs match their peers in each compound due to their similar hydrophobic core structures. Cholesterol is depicted in pink (A), yellow (B) and white color (C). Compound A carbon atoms are represented in green color, blue color for nitrogen atoms $(\mathrm{N})$, and red color for oxygen $(\mathrm{O})$.

fibroblasts. MCF-7 is an estrogen receptor positive cell line. The biological effects of estrogen are mediated through either the alpha or the beta receptor. It has been demonstrated that PI3K is necessary for the estrogen signaling, in addition, PI3K is one of the key enzymes which regulates phosphoinositide metabolism and is responsible for generation of phosphatidylinositol-3,4,5-trisphosphate (PIP3) via phosphorylation of D-3 position of the inositol ring of (PIP2). The activation of PI3K results in PIP3-mediated activation of serinethreonine kinase Akt by phosphorylation. The Akt protein in turn modulates the function of many substrates involved in the regulation of cell functions including proliferation and cell cycle progression. ${ }^{36}$ That is why MCF-7 cell line was selected to investigate the cytotoxicity effect of the PI3K inhibitor (Compound A) alone and upon conjugation with GNRs decorated with cholesterol-PEG moiety (the nanocomplex).

The $\mathrm{IC}_{50}$ of Compound A $\left(235.9 \mu \mathrm{g} \mathrm{mL}^{-1}\right)$ was determined over the concentration range of $0.97-500 \mu \mathrm{g} \mathrm{mL}^{-1}$ against MCF7 breast cancer cells (Fig. 7).

Fig. 8A shows the percentage of cellular viability of MCF-7 upon treatment with the nanocomplex (Chol-A-GNRs), free Compound $\mathrm{A}$ and the nanocarrier (Chol-GNRs). Interestingly, the nanocomplex revealed potent cytotoxicity over very low range of concentrations $(10.0 / 12.5,2.5 / 3.125$ and $0.625 /$ $0.75 \mu \mathrm{g} \mathrm{mL}^{-1}$ of Chol-GNRs/Compound A). For example, at concentration of $\sim 3.125 \mu \mathrm{g} \mathrm{mL}{ }^{-1}$ of Compound A in Chol-AGNRs, the nanocomplex exhibited cellular viability of only about $20 \%$ compared to around $70 \%$ for the nanocarrier alone ( $\sim 3.5$ folds), and around $100 \%$ for the free compound at the same concentration ( 5 folds). Interestingly, the effective concentrations of Compound $\mathrm{A}$ in the nanocomplex were significantly less than the $\mathrm{IC}_{50}$ of Compound A alone against MCF-7 breast cancer cells.
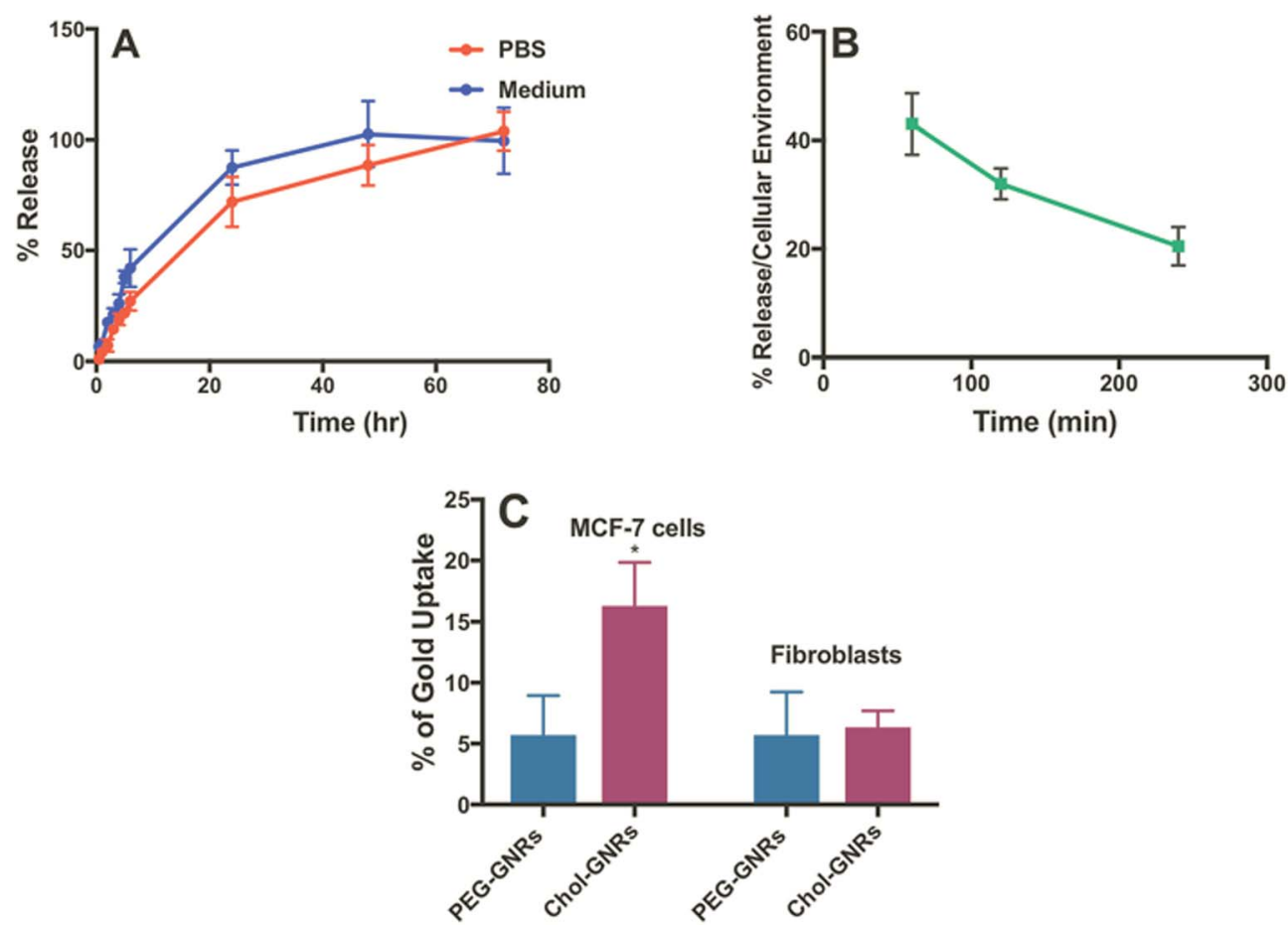

Fig. 6 In vitro release profile of Compound A from the nanocomplex (Chol-A-GNRs) in PBS and in tissue culture medium (A). Release profile of Compound A from the nanocomplex (Chol-A-GNRs) under cellular environment (B). Percentages of cellular uptake of Chol-GNRs and PEGGNRs into MCF-7 breast cancer cells and human dermal fibroblasts (C). Data are presented as mean \pm SD, $n=3$. Unpaired $t$-test was used to assess the differences; * represent $p<0.05$. 


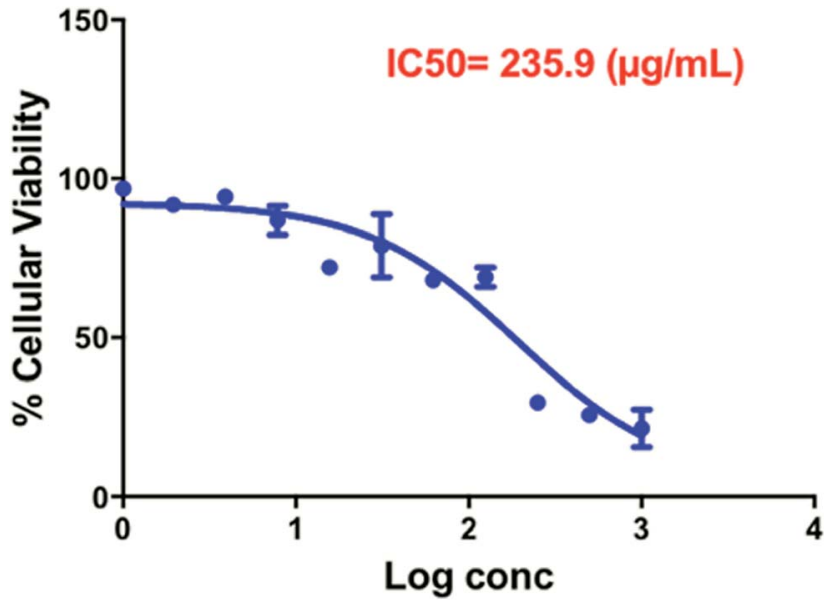

Fig. 7 Estimation of $\mathrm{IC}_{50}$ of free Compound A over the concentration range of $0.97-500 \mu \mathrm{g} \mathrm{mL}^{-1}$ against MCF-7 breast cancer cells (results present the average and standard deviation of three determinations).

The cellular viability of the nanocarrier (Chol-GNRs) against MCF-7 cells was around $40 \%$ at the highest concentration used, which may be due to the detected cellular uptake of Chol-GNRs ( $\sim 15 \%)$ into MCF-7 cells in particular at high concentration.

Its worth's to note that the nanocomplex at high concentration $\left(40.0 / 50 \mu \mathrm{g} \mathrm{mL}^{-1}\right.$ of Chol-GNRs/Compound A) demonstrated no significant antiproliferative activity (data not shown). This could be attributed to the poor colloidal stability of the nanocomplex upon mixing with the tissue culture medium at high concentration compared to low concentrations (as indicated by the obvious aggregation of the nanocomplex in the medium). Nanoparticles in solution generally have a high tendency to increase in size due to rapid collision of particles, van der Waals bonding and water bridging. ${ }^{37}$

Interestingly, no appreciable cytotoxicity was observed for the free compound, free nanocarrier nor the nanocomplex against normal human dermal fibroblasts over the same concentration range used against the cancer cells (Fig. 8B). As shown in Fig. 6C, the cellular uptake of the nanocarrier (CholGNRs) into the human dermal fibroblasts (healthy cells) was significantly less than that observed for the cancerous cells $(7 \%$ vs. $15 \%$ ) which might explain their observed safety profile upon application to the normal cells.

Cancer cells in general have fundamental differences in the composition, amount and arrangement of phospholipids and cholesterol in the cell membrane compared to the normal cells. ${ }^{38}$ Cholesterol (cholest-5-en-3-ol) is a rigid planar molecule with a steroid skeleton of four fused rings, three six-membered and one five-membered, and is one of the most important structural components of the cell membrane. ${ }^{39}$ Furthermore, the presence of cholesterol in the cell membrane is abundant, and it plays a key role in the membrane integrity and fluidity, ${ }^{40}$ however, it has been reported that malignant cells have elevated levels of cholesterol precursors. ${ }^{41}$ Breast and prostate cancer cell lines have elevated amount of lipid rafts and they are more sensitive to cell death caused by cholesterol depletion compared to the healthy cells. ${ }^{42}$

We suppose that the nanocarrier (Chol-GNRs) which composed of a cholesterol moiety may enhanced the adsorption of the nanocomplex into the lipid cell membrane of the breast cancer cells compared to normal cells, and subsequently enhanced the uptake of the loaded hydrophobic ligand. Besides, the observed cellular uptake of the nanocarriers themselves may also contribute to the detected massive uptake of Compound A into the cells. This also could explain the little toxicity of the nanocomplex against human dermal fibroblasts and their preferential cellular uptake into the cancer cells. Moreover, Compound A was designated as PI3K $\alpha$ inhibitory agent for a targeted therapy of cancers that demonstrated an elevated activation of PI3K $\alpha$. Breast cancer was found to be highly associated with a pathologic activation of PI3K $\alpha$ pathway compared to healthy cells. ${ }^{43}$

Employment of cholesterol and lipids for drug delivery was demonstrated in the literature. Among various lipid-based formulations, liposomes have demonstrated efficiency in several biomedical applications. ${ }^{\mathbf{4 4}}$ Furthermore, lipid conjugated to a polymer possess several characteristics that make them highly suitable for drug delivery for diverse of hydrophobic anti-cancer drugs. ${ }^{45}$ Moreover, cholesterol-coupled to poly(D,L-lactide)-micelles were used for efficient delivery of curcumin into melanoma and breast cancer cell. ${ }^{46}$

\subsection{Analysis of cell death modality of MCF-7 cells upon treatment with Chol-A-GNRs by flow cytometry}

3.7.1 Apoptosis analysis. To determine cell death modality, MCF-7 cells pre-treated with nanocomplex (Chol-A-GNRs) were examined after $24 \mathrm{~h}$ of treatment using flow cytometry.

The results indicate that the nanocomplex (Chol-A-GNRs) significantly reduced the cell viability of MCF-7 cells compared to the control untreated cells. Interestingly, both 4.0 and $8.0 \mu \mathrm{g} \mathrm{mL} \mathrm{m}^{-1}$ of the nanocomplex showed similar decrease in the percentage of viable cells; $\sim 31.47 \%$ and $\sim 32.14 \%$, respectively, compared to the control untreated cells; $\sim 58.72 \%$ $(P<0.05)$ (Fig. 9A-D). On the other hand, $8.0 \mu \mathrm{g} \mathrm{mL}{ }^{-1}$ of the treatment was able to increase the percentage of necrotic population statistically by 3.35 folds compared to the untreated cells $(\sim 58.77 \%$ vs. $\sim 17.5 \%$ respectively, $P<0.05)$, while $4.0 \mu \mathrm{g}$ $\mathrm{mL}^{-1}$ of the treatment showed only 1.5 folds change compared to the untreated cells $(\sim 25.94 \%$ vs. $\sim 17.5 \%$, respectively) (Fig. 9A-D).

On the contrary, the percentage of late apoptotic population

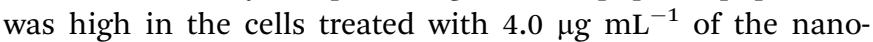
complex, as the percentage was increased by 13 folds compared to the control ( $\sim 34.15 \%$ vs. $\sim 2.56 \%$, respectively, $P<0.05)$. On the other hand, the nanocomplex of $8.0 \mu \mathrm{g} \mathrm{mL} \mathrm{m}^{-1}$ showed only 3.37 folds change compared to the untreated cells $(\sim 8.630 \% v s$. average of $\sim 2.56 \%$, respectively) (Fig. 9A-D).

Quite the opposite of late stages; early apoptotic population was larger in the control untreated cells (average of $\sim 19.18 \%$ ) compared to the cells treated with the nanocomplex. The cells treated with 4.0 or $8.0 \mu \mathrm{g} \mathrm{mL}^{-1}$ of the nanocomplex showed low 

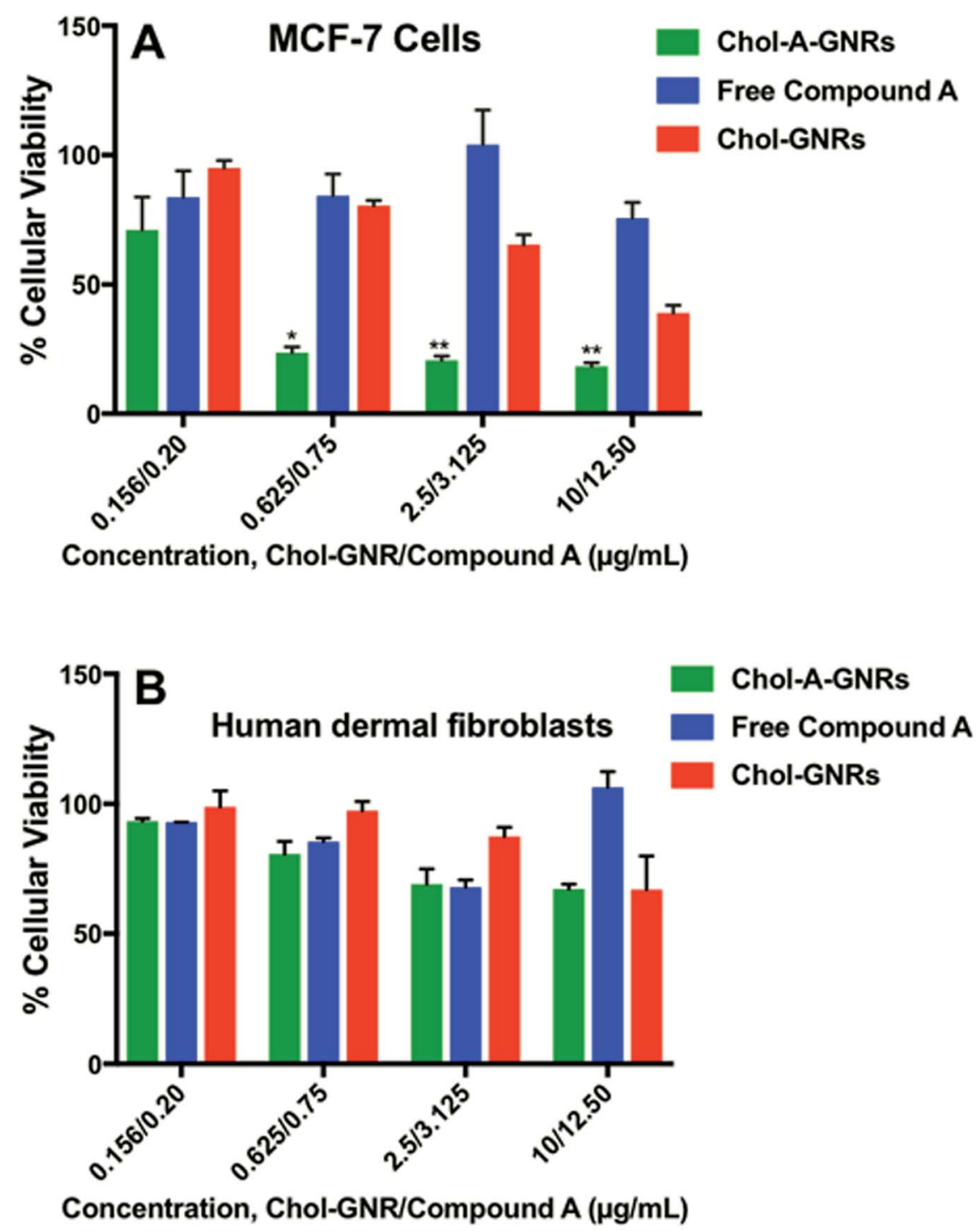

Fig. 8 Anti-proliferative activity of the nanocomplex (Chol-A-GNRs), free Compound A, and the nanocarrier (Chol-GNRs) against MCF-7 breast cancer cells (A) and human dermal fibroblasts (B). The nanocomplex demonstrates potent anti-proliferative activity against MCF-7 cells over low range of concentrations compared to human dermal fibroblasts. Data are given as mean $\pm \mathrm{SD}, n=3$. Unpaired $t$-test was used to assess the differences; * represent $p<0.05, * *$ represents $p<0.01$.

percentages of early apoptotic cells (average of $\sim 8 \%$ and $\sim 0.455 \%$, respectively) (Fig. 9A-D). This is clearly explained by the rapid effect of the nanocomplex on cell death, as cells went through early apoptotic stage toward late apoptotic/necrotic stage rapidly and proportionally to the increase of the nanocomplex concentration.

Consequently, we concluded that the nanocomplex has direct impact on cell death modality and this effect is a concentration dependent.

3.7.2 Cell cycle analysis. Regarding the cell death modality results; $8.0 \mu \mathrm{g} \mathrm{mL} \mathrm{mL}^{-1}$ of the nanocomplex showed the highest percentage of cell death. Therefore, flow cytometric analysis was conducted to investigate whether the treatment could induce perturbations in the cell cycle of MCF-7 cells.
Cell cycle parameters of cells treated with $8.0 \mu \mathrm{g} \mathrm{mL}^{-1}$ of the nanocomplex were compared to the control (untreated cells). As shown in Fig. 10, our results interestingly show a significant difference in the proportion of cells in G0/G1, S and $\mathrm{G} 2 / \mathrm{M}$ phases when cells were treated with $8.0 \mu \mathrm{g} \mathrm{mL} \mathrm{m}^{-1}$ of the nanocomplex compared to the untreated cells $(P<0.05)$. As cells treated with the aforementioned treatment showed $100 \%$ arrest at G0/G1 phases and were unable to go through other cell cycle phases (S and G2/M phases) (Fig. 10A). While untreated cells did not show any perturbations in the cell cycle phases (Fig. 10B). Thus, this arrest might be resulted in the activation of different pathways that lead to the programmed cell death. ${ }^{47,48}$

As a result, we indicate that the nanocomplex is considered as a strong inhibitor for cell cycle progression. 

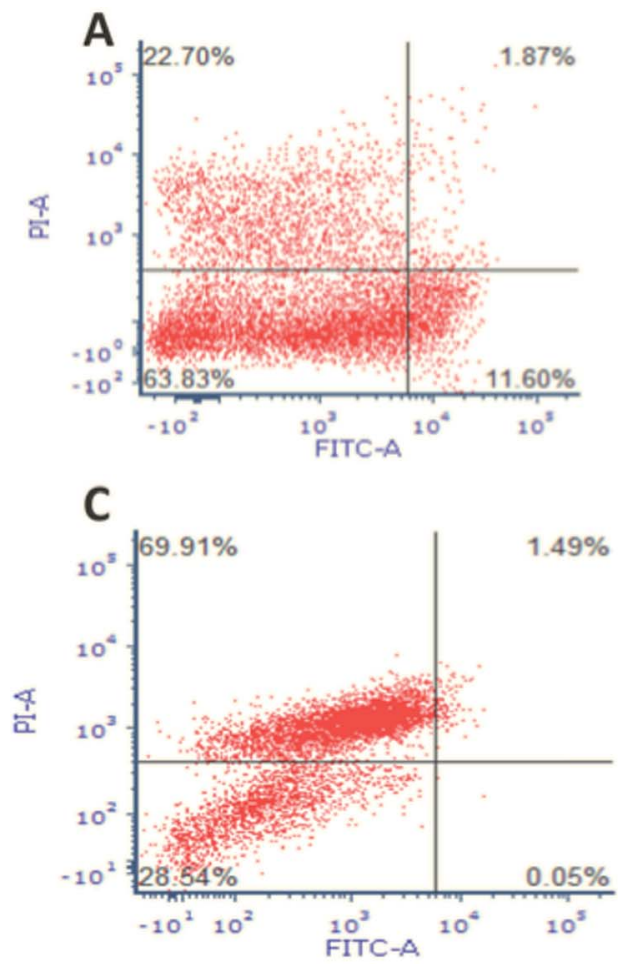

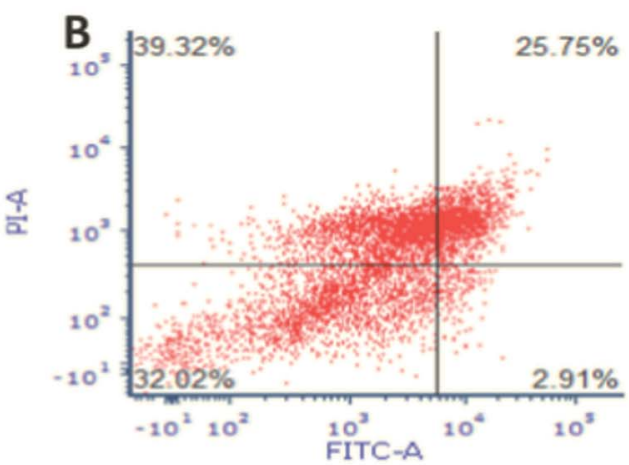

D

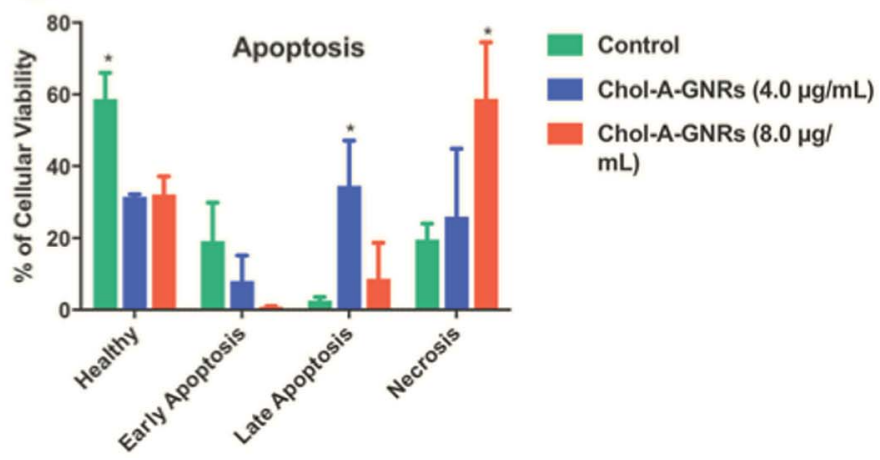

Fig. 9 Flow cytometry assay of apoptosis of the control untreated MCF-7 cells (A); MCF-7 cells incubated for $24 \mathrm{~h}$ in the presence of $4.0 \mu \mathrm{g} \mathrm{mL}$ (B) and $8.0 \mu \mathrm{g} \mathrm{mL}^{-1}$ (C) of the nanocomplex and stained with FITC-conjugated annexin $\mathrm{V}$ and PI-stained. The dot plot for each sample was divided into four quadrants to indicate viable cells (lower left quadrant), early apoptotic cells (lower right quadrant), necrotic cells (upper left quadrant), and late apoptotic cells (upper right quadrant). A significant difference was observed in the percentage of necrotic and late apoptotic cells upon treating the MCF-7 cells with $8.0 \mu \mathrm{g} \mathrm{mL}^{-1}$ and $4.0 \mu \mathrm{g} \mathrm{mL}^{-1}$ of the nanocomplex, respectively compared to the untreated cells $(P<$ 0.05). Data are presented as mean $\pm S D, n=3$ (D). Unpaired $t$-test was used to assess the differences; * represent $p<0.05$. (A) $-(C)$ Plots are examples of one run of the analysis.

A



B

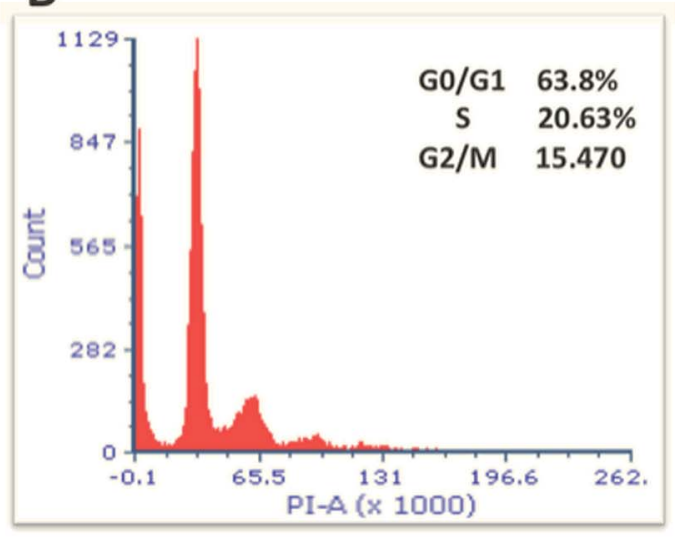

Fig. 10 Flow cytometric analysis of cell cycle parameters. MCF-7 cells were incubated for $24 \mathrm{~h}$; in the presence of $8.0 \mu \mathrm{g} \mathrm{mL} \mathrm{L}^{-1}$ of the nanocomplex (A) and without additive of treatment (untreated) (B). Cells were stained with propidium iodide for analysis by flow cytometry. The cells treated with the nanocomplex showed $100 \%$ arrest at G0/G1 phases. A statistical difference was observed between MCF-7 cells treated with the nanocomplex and their control untreated cells $(P<0.05)$. Data are given as means, $n=3$, and unpaired $t$-test was used to assess the difference.

\section{Conclusions}

Effective delivery of hydrophobic chemotherapeutic agents is considered as a real challenge in cancer therapy. Gold-based nanocarriers have a distinguished role in competent and efficient drug delivery. In this study, a facile and simple GNRs decorated with cholesterol moiety was utilized as a promising nanocarrier to conjugate a small hydrophobic ligand, having a PI3K $\alpha$ inhibitory activity, into the hydrophobic pocket of the nanocarrier. The acquired nanocomplex possess an accelerated 
release of the ligand under cellular environment and exhibited potent anti-proliferative activity over low range of concentrations. Furthermore, the nanocomplex demonstrated a potent inhibition of the cell cycle and hastened the cellular apoptotic/ necrotic events. Further investigations are needed to understand the specific pathways responsible for such observed potent cytotoxic features of the nanocomplex.

\section{Conflicts of interest}

There are no conflicts to declare.

\section{Acknowledgements}

Authors acknowledge the Deanship of Scientific Research and Graduate Studies at Al-Zaytoonah University of Jordan Grant (2017-2016/64/04), and The Scientific Research Support Fund (MPH/1/15/2015), Amman, Jordan, for financial funding.

\section{Notes and references}

1 Z. Anastasiadi, G. D. Lianos, E. Ignatiadou, H. V. Harissis and M. Mitsis, Updates in surgery, 2017, 69, 313-317.

2 K. Sak, Chemother. Res. Pract., 2012, 2012, 282570.

3 A. H. Partridge, H. J. Burstein and E. P. Winer, J. Natl. Cancer Inst. Monogr., 2001, 135-142.

4 Q. Mu, H. Wang and M. Zhang, Expert Opin. Drug Delivery, 2017, 14, 123-136.

5 S. K. Singh, S. Singh, J. W. Lillard Jr and R. Singh, Int. J. Nanomed., 2017, 12, 6205-6218.

6 S. S. Qi, J. H. Sun, H. H. Yu and S. Q. Yu, Drug Delivery, 2017, 24, 1909-1926.

7 R. X. Zhang, H. L. Wong, H. Y. Xue, J. Y. Eoh and X. Y. Wu, J. Controlled Release, 2016, 240, 489-503.

8 E. J. Feldman, J. E. Lancet, J. E. Kolitz, E. K. Ritchie, G. J. Roboz, A. F. List, S. L. Allen, E. Asatiani, L. D. Mayer, C. Swenson and A. C. Louie, J. Clin. Oncol., 2011, 29, 979-985.

9 J. R. Hasenstein, H. C. Shin, K. Kasmerchak, D. Buehler, G. S. Kwon and K. R. Kozak, Mol. Cancer Ther., 2012, 11, 2233-2242.

10 H. C. Shin, A. W. Alani, H. Cho, Y. Bae, J. M. Kolesar and G. S. Kwon, Mol. Pharmaceutics, 2011, 8, 1257-1265.

11 H. C. Shin, H. Cho, T. C. Lai, K. R. Kozak, J. M. Kolesar and G. S. Kwon, J. Controlled Release, 2012, 163, 93-99.

12 S. Anniebell and S. C. B. Gopinath, Curr. Med. Chem., 2018, 25, 1433-1445.

13 H. Daraee, A. Eatemadi, E. Abbasi, S. Fekri Aval, M. Kouhi and A. Akbarzadeh, Artif. Cells, Nanomed., Biotechnol., 2016, 44, 410-422.

14 J. Lee, D. K. Chatterjee, M. H. Lee and S. Krishnan, Cancer Lett., 2014, 347, 46-53.

15 A. O. Elzoghby, A. L. Hemasa and M. S. Freag, J. Controlled Release, 2016, 243, 303-322.

16 Y. Ding, Z. Jiang, K. Saha, C. S. Kim, S. T. Kim, R. F. Landis and V. M. Rotello, Mol. Ther., 2014, 22, 1075-1083.

17 V. S. Marangoni, J. Cancino-Bernardi and V. Zucolotto, J. Biomed. Nanotechnol., 2016, 12, 1136-1158.
18 R. A. Morshed, M. E. Muroski, Q. Dai, M. L. Wegscheid, B. Auffinger, D. Yu, Y. Han, L. Zhang, M. Wu, Y. Cheng and M. S. Lesniak, Mol. Pharmaceutics, 2016, 13, 1843-1854.

19 S. Balakrishnan, S. Mukherjee, S. Das, F. A. Bhat, P. Raja Singh, C. R. Patra and J. Arunakaran, Cell Biochem. Funct., 2017, 35, 217-231.

20 C. K. Kim, P. Ghosh, C. Pagliuca, Z. J. Zhu, S. Menichetti and V. M. Rotello, J. Am. Chem. Soc., 2009, 131, 1360-1361.

21 D. A. Sabbah, B. Hishmah, K. Sweidan, S. Bardaweel, M. AlDamen, H. A. Zhong, R. Abu Khalaf, A. Hasan Ibrahim, T. Al-Qirim, G. Abu Sheikha and M. S. Mubarak, Anti-Cancer Agents Med. Chem., 2018, 18, 263-276.

22 B. Vanhaesebroeck and M. D. Waterfield, Exp. Cell Res., 1999, 253, 239-254.

23 B. Vanhaesebroeck, J. Guillermet-Guibert, M. Graupera and B. Bilanges, Nat. Rev. Mol. Cell Biol., 2010, 11, 329-341.

24 X. Ye, C. Zheng, J. Chen, Y. Gao and C. B. Murray, Nano Lett., 2013, 13, 765-771.

25 R. A. Friesner, J. L. Banks, R. B. Murphy, T. A. Halgren, J. J. Klicic, D. T. Mainz, M. P. Repasky, E. H. Knoll, M. Shelley, J. K. Perry, D. E. Shaw, P. Francis and P. S. Shenkin, J. Med. Chem., 2004, 47, 1739-1749.

26 R. A. Friesner, R. B. Murphy, M. P. Repasky, L. L. Frye, J. R. Greenwood, T. A. Halgren, P. C. Sanschagrin and D. T. Mainz, J. Med. Chem., 2006, 49, 6177-6196.

27 Protein Preparation Wizard, Maestro, Macromodel, and QPLDdock, Schrödinger, LLC, Portland, OR, USA, 97204, 2016.

28 D. A. Sabbah, J. L. Vennerstrom and H. A. Zhong, J. Chem. Inf. Model., 2012, 52, 3213-3224.

29 C.-H. Huang, D. Mandelker, O. Schmidt-Kittler, Y. Samuels, V. E. Velculescu, K. W. Kinzler, B. Vogelstein, S. B. Gabelli and L. M. Amzel, Science, 2007, 318, 1744-1748.

30 A. M. Alkilany, P. K. Nagaria, C. R. Hexel, T. J. Shaw, C. J. Murphy and M. D. Wyatt, Small, 2009, 5, 701-708.

31 K. Nishida and H. Kawasaki, RSC Adv., 2017, 7, 18041-18045. 32 A. S. Karakoti, S. Das, S. Thevuthasan and S. Seal, Angew. Chem., Int. Ed. Engl., 2011, 50, 1980-1994.

33 J. S. Suk, Q. Xu, N. Kim, J. Hanes and L. M. Ensign, Adv. Drug Delivery Rev., 2016, 99, 28-51.

34 H. Hinterwirth, S. Kappel, T. Waitz, T. Prohaska, W. Lindner and M. Lämmerhofer, ACS Nano, 2013, 7, 1129-1136.

35 F. Ren, S. Bhana, D. D. Norman, J. Johnson, L. Xu, D. L. Baker, A. L. Parrill and X. Huang, Bioconjugate Chem., 2013, 24, 376-386.

36 Y. R. Lee, J. Park, H. N. Yu, J. S. Kim, H. J. Youn and S. H. Jung, Biochem. Biophys. Res. Commun., 2005, 336, 1221-1226.

37 C. P. Tso, C. M. Zhung, Y. H. Shih, Y. M. Tseng, S. C. Wu and R. A. Doong, Water Sci. Technol., 2010, 61, 127-133.

38 C. R. Santos and A. Schulze, FEBS J., 2012, 279, 2610-2623.

39 N. M. Cerqueira, E. F. Oliveira, D. S. Gesto, D. SantosMartins, C. Moreira, H. N. Moorthy, M. J. Ramos and P. A. Fernandes, Biochemistry, 2016, 55, 5483-5506.

40 J. M. Crane and L. K. Tamm, Biophys. J., 2004, 86, 2965-2979. 41 R. E. Duncan, A. El-Sohemy and M. C. Archer, J. Biol. Chem., 2004, 279, 33079-33084. 
42 Y. C. Li, M. J. Park, S. K. Ye, C. W. Kim and Y. N. Kim, Am. J. Pathol., 2006, 168, 1107-1118.

43 S. X. Yang, E. Polley and S. Lipkowitz, Cancer Treat. Rev., 2016, 45, 87-96.

44 L. Sercombe, T. Veerati, F. Moheimani, S. Y. Wu, A. K. Sood and S. Hua, Front. Pharmacol., 2015, 6, 286.

45 J. H. Kang and Y. T. Ko, Int. J. Nanomed., 2015, 10(spec iss), 33-45.
46 P. Kumari, O. S. Muddineti, S. V. Rompicharla, P. Ghanta, A. K. B B N, B. Ghosh and S. Biswas, Drug Delivery, 2017, 24, 209-223.

47 J. A. Pietenpol and Z. A. Stewart, Toxicology, 2002, 181-182, 475-481.

48 B. Pucci, M. Kasten and A. Giordano, Neoplasia, 2000, 2, 291299. 